\title{
Design and Implementation Procedure of a High-Gain Three-Input Step-Up 1 kW Converter
}

\author{
Edgardo Netzahuatl-Huerta (D), Leobardo Hernandez-Gonzalez *iD, Domingo Cortes (D) \\ and Jazmin Ramirez-Hernandez (D)
}

Instituto Politécnico Nacional, Escuela Superior de Ingenieria Mecanica y Electrica, Unidad Culhuacan, Av. Santa Ana No. 1000, Col. San Francisco Culhuacan, Mexico City C.P. 04430, Mexico; edgardo.netz@gmail.com (E.N.-H.); domingo.cortes@gmail.com (D.C.); jazzrh@hotmail.com (J.R.-H.)

* Correspondence: lhernandezg@ipn.mx

Citation: Netzahuatl-Huerta, E.; Hernandez-Gonzalez, L.; Cortes, D.; Ramirez-Hernandez, J. Design and Implementation Procedure of a High-Gain Three-Input Step-Up $1 \mathrm{~kW}$ Converter. Electronics 2021, 10, 625. https://doi.org/10.3390/electronics 10050625

Academic Editor: Ki-Bum Park

Received: 11 January 2021

Accepted: 5 March 2021

Published: 8 March 2021

Publisher's Note: MDPI stays neutral with regard to jurisdictional claims in published maps and institutional affiliations.

\begin{abstract}
The use of different sources to energize a load is convenient in many applications, particularly those where two or more renewable energy sources are employed, such as energy harvesting, hybrid vehicles, and off-grid systems. In these cases, a multi-input converter is able to admit sources with different characteristics and, if necessary, select the output power of each source. Several topologies of multi-input converters have been proposed to this aim; however, most of them are based on multistage designs, which decreases efficiency and increases control complexity, particularly when more than two sources are used. In this work, a three-input step-up converter, easy to control in open loop condition, is analyzed. A designed procedure is described, and experimental results are presented for a $1 \mathrm{~kW}$ power converter. The implemented converter results in a higher voltage gain and less storage element, keeping high efficiency compared to similar topologies. Using the procedure here proposed, this converter that was initially designed for photovoltaic applications is enabled to be used in medium- and high-power applications, for example, when renewable energy sources are used.
\end{abstract}

Keywords: multi-output converter; DC-DC converter; boost converter; renewable energy

\section{Introduction}

An intense research effort has been made to increase the use of renewable energy in all human activities. Techniques to take advantage of solar [1], wind [2] and hydrogen-based energy [3], among other clean energies, have been developed. In some applications, it is necessary to jointly use several of these sources to feed a single load. Frequently, it is a convenient scheme where, if a single source is not enough, a second source may be used; if both are not sufficient, a third can be used, and so on. To make such scheme possible, a multi-input converter is necessary [4]. Among the applications where this scheme is used are energy harvesting for wireless sensors [5], smart buildings [6], hybrid and electric vehicles [7], off-grid systems in rural areas [8], etc.

Multi-input step-up converters have been reported in the literature; some of them are based on the boost converter. For example, experimental results for a multi-input multi-output step-up converter for a $1 \mathrm{~kW}$ prototype are presented in [9]; this topology presents some disadvantages, like a high number of energy storage elements and a low switching frequency operation, that increase the magnetic component's size. In [10], a dual-input step-up converter is presented for a $125 \mathrm{~W}$ prototype with a high efficiency of $97 \%$, but the number of switching power devices are two per input. The number of semiconductor devices increases severely in the dual step-up converter presented in [11] for a $200 \mathrm{~W}$ output power and an efficiency of $87 \%$.

In [12], a model for the dual-input case of the topology proposed in [13] was derived and analyzed, and a $500 \mathrm{~W}$ converter was evaluated. However, the real difficulty with the existing multi-input converters arises when more than two inputs are used, and a higher 
power is required. In this context, to make sure that the model and design procedure match the experimental results, a $1 \mathrm{~kW}$ prototype for three input voltages is implemented in this work, considering an open loop control. Efficiency and reliability of the converter are also evaluated.

\section{Principle of Operation}

The converter analyzed in this paper is shown in Figure 1. It was first proposed in [13] for a low power application $(100 \mathrm{~W})$ for two inputs. The number of components is one MOSFET to each input source added; in this case, three input voltages are considered: $V_{\text {in } 1}$, $V_{\text {in } 2}$ and $V_{\text {in } 3}$. Since the basic construction block is the boost converter, the only added component per input is a capacitor. To obtain the control switching signals, two basic conditions need to be considered: the phase shift in the control signals, $\varphi=360^{\circ} /$ inputs $=$ $360^{\circ} / 3=120^{\circ}$, and the minimum duty cycle, which is given by $d_{\min }=1-(1 /$ inputs $)=0.66$.

The six operating modes are shown in Figure 1. The control signals that generate these modes (M1 to M6) are presented in Figure 2. The control signals for $d_{\text {min }}$ are indicated in red; it can be observed that, at any timeframe, there are two switches in conduction, at most.

To analyze the operation of each mode, the following initial conditions are considered: $I_{L 1}, I_{L 2}$ and $I_{L 3}$ currents are greater than zero, and $C_{1}$ and $C_{2}$ are charged to $+V_{C 1}$ and $+V_{C 2}$. The conditions in each operating mode are as follows:

Mode 1, $\Delta t_{1}$ (see Figure 1a): This mode starts by turning on switches $S 1, S 2$ and $S 3$ at the same timeframe; diodes $D_{1}, D_{2}$ and $D_{3}$ are state-off. In this interval, inductors $L_{1}, L_{2}$ and $L_{3}$ are charged by $V_{\text {in } 1}, V_{\text {in } 2}$ and $V_{\text {in } 3}$, respectively. Currents $I_{L 1}, I_{L 2}$ and $I_{L 3}$ increase linearly from its minimum value to its maximum. Considering that the average currents through capacitor $C_{1}, C_{2}$ and $C_{o}$ are zero, voltages $V_{C 1}, V_{C 2}$ and $V_{C o}$ are constant. This mode ends when switch $S 2$ is turned off at $\Delta t_{2}$.

Mode 2, $\Delta t_{2}$ (see Figure $1 b$ ). In this mode, $S 2$ is turned off, and $D_{2}$ is activated, allowing current of inductor $L_{2}$ flows through $C_{1}$ and $C_{2}$. Thus, $I_{L 2}$ decreases linearly and charges $C_{1}$ and $C_{2}$, increasing their voltages. This mode ends when switch $S 2$ is turned on at $\Delta t_{3}$.

Mode 3, $\Delta t_{3}$ (see Figure 1c). This mode is the same as mode 1.

Mode $4, \Delta t_{4}$ (see Figure $1 \mathrm{~d}$ ). In this mode, $S 3$ is turned off, and $D_{3}$ is activated, allowing the current of inductor $L_{3}$ flows through $C_{2}$. Thus, $I_{L 3}$ decreases linearly and charges $C_{2}$. This mode ends when switch $S 3$ is gated ON at $\Delta t_{5}$.

Mode $5, \Delta t_{5}$ (see Figure 1e). This mode is the same as mode 1.

Mode 6, $\Delta t_{6}$ (see Figure 1f). In this mode, $S 1$ is turned off, and $D_{1}$ is activated, allowing the current of inductor $L_{1}$ flows through $C_{1}$ and $C_{o}$. Hence $I_{L 1}$ decreases linearly and begins to charge $C_{0}$; at the same timeframe, $C_{1}$ is discharged to $R_{L}$. This mode ends when switch $S 1$ is gated $\mathrm{ON}$.

Although modes 1, 3 and 5 are the same, they are shown for completeness.

Converter stationary ideal waveforms obtained from analysis of its six operation modes are qualitative depicted in Figure 3.

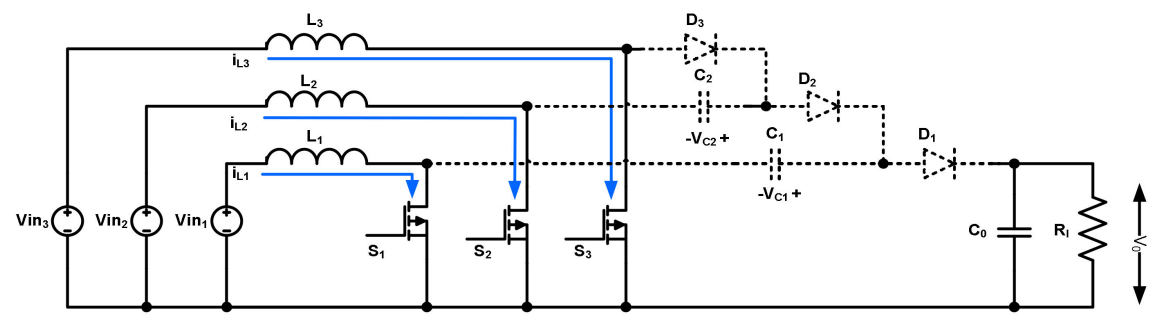

(a)

Figure 1. Cont. 


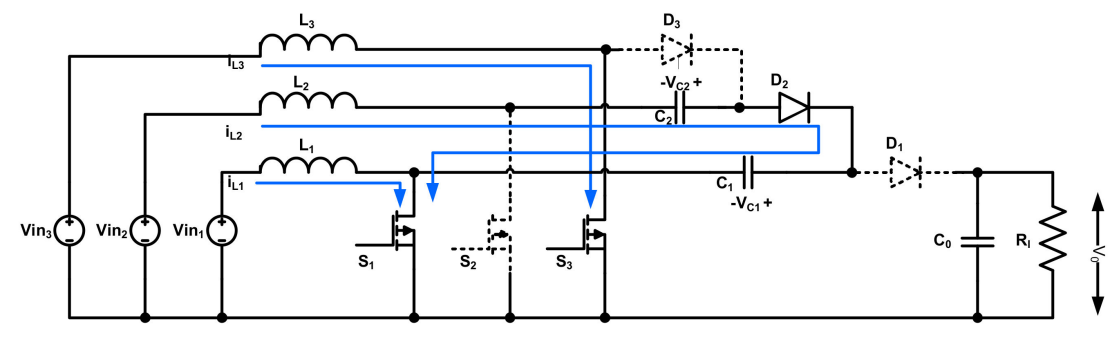

(b)

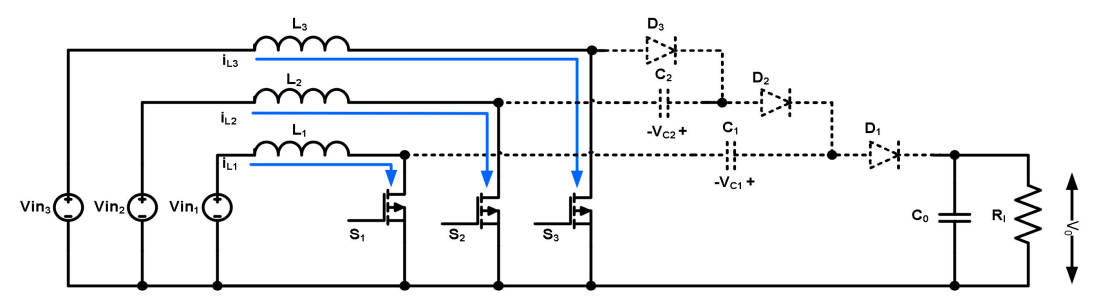

(c)

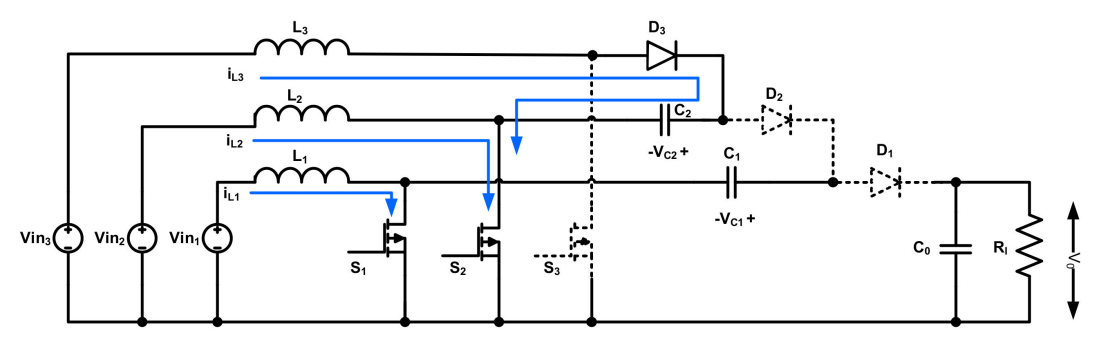

(d)

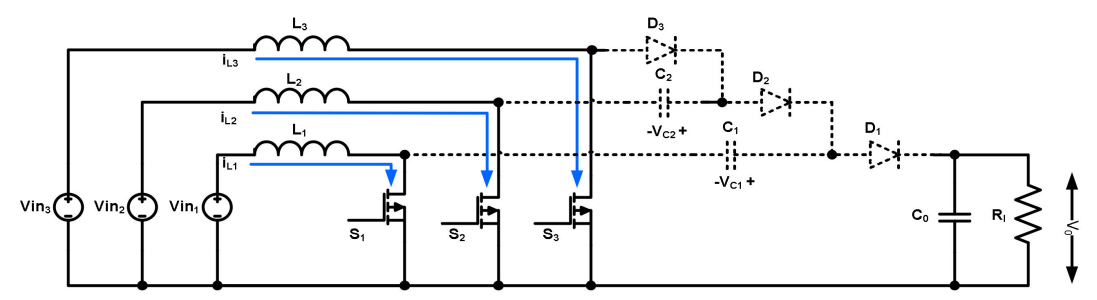

(e)

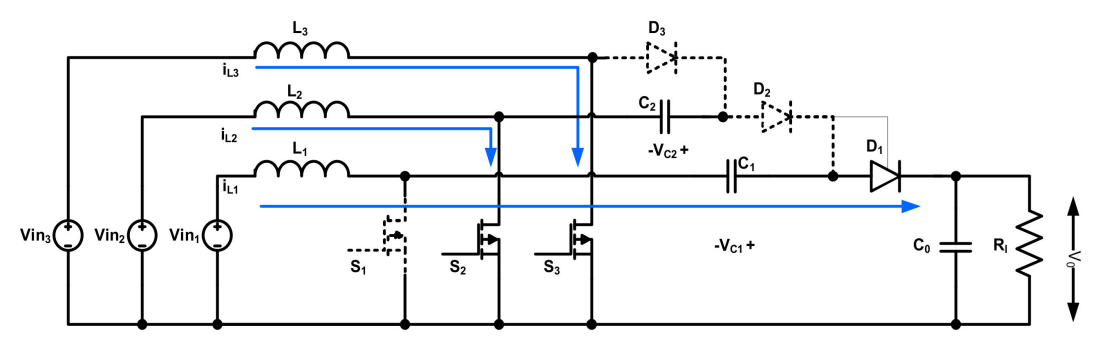

(f)

Figure 1. Operating modes of the three-input step-up converter: (a) Mode 1, $S 1=S 2=S 3=O n$, (b) Mode 2, S1 = S3 = On, S2 = Off, (c) Mode 3, S1 = S2 = S3 = On, (d) Mode 4, S1 = S2 = On, S3 = Off, (e) Mode 5, S1 = S2 = S3 = On, (f) Mode 6, S2 = S3 = On, S1 = On. 


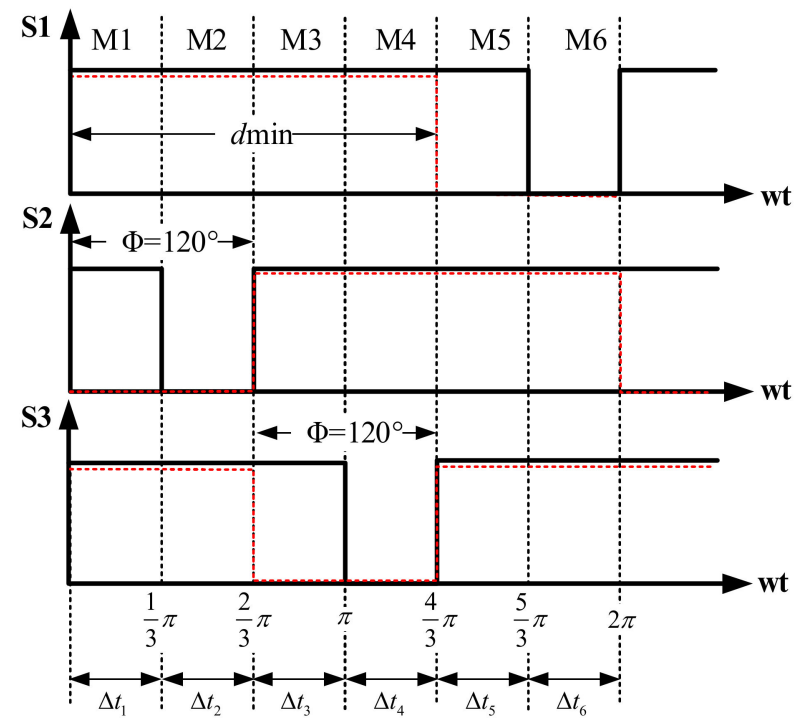

Figure 2. Control signals and operating modes in the three-input step-up converter.

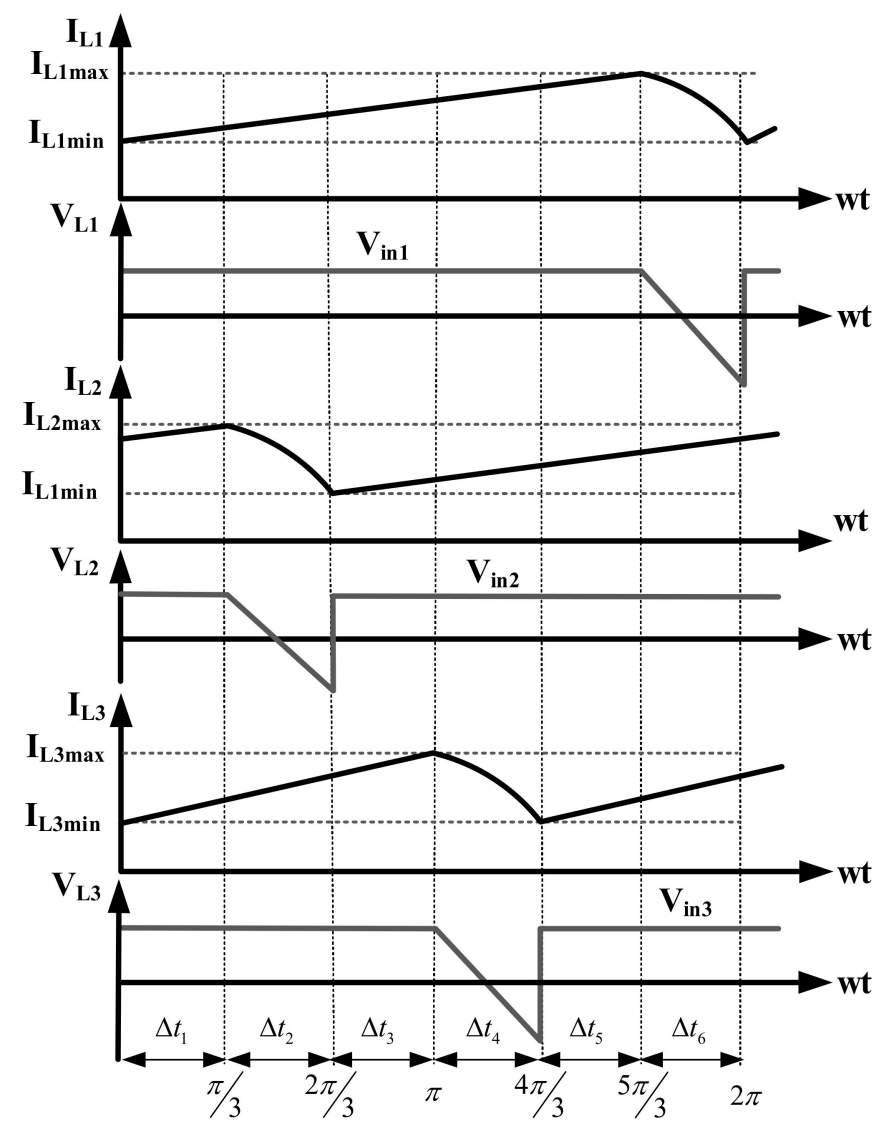

Figure 3. Ideal waveforms of three-input step-up converter.

Model Based on a State Variable Equations

To obtain a model of the converter based on the state space analysis, the state variables are chosen according to:

$$
\begin{aligned}
& x_{1}=I_{L_{1}}, \\
& x_{2}=I_{L_{2}},
\end{aligned}
$$




$$
\begin{aligned}
& x_{3}=I_{L_{3}}, \\
& x_{4}=V_{C_{1}}, \\
& x_{5}=V_{C_{2}}, \\
& x_{6}=V_{C_{o}}
\end{aligned}
$$

According to the procedure described in [12], the state space equations for the six operating modes are shown in Table 1.

Table 1. State space equations.

\begin{tabular}{cccc}
\hline Modes 1, 3,5 & Mode 2 & Mode 4 & Mode 6 \\
\hline$\dot{x}_{1}=\frac{V_{i n 1}}{L_{1}}$ & $\dot{x}_{1}=\frac{V_{i n 1}}{L_{1}}$ & $\dot{x}_{1}=\frac{V_{i n 1}}{L_{1}}$ & $\dot{x}_{1}=\frac{V_{i n 1}}{L_{1}}+\frac{x_{4}}{L_{1}}-\frac{x_{6}}{L_{1}}$ \\
$\dot{x}_{2}=\frac{V_{i n_{2}}}{L_{2}}$ & $\dot{x}_{2}=\frac{V_{i n_{2}}}{L_{2}}-\frac{x_{4}}{L_{2}}+\frac{x_{5}}{L_{2}}$ & $\dot{x}_{2}=\frac{V_{i n_{2}}}{L_{2}}$ & $\dot{x}_{2}=\frac{V_{i n_{2}}}{L_{2}}$ \\
$\dot{x}_{3}=\frac{V_{i n_{3}}}{L_{3}}$ & $\dot{x}_{3}=\frac{V_{i n_{3}}}{L_{3}}$ & $\dot{x}_{3}=\frac{V_{i n_{3}}}{L_{3}}-\frac{x_{5}}{L_{3}}$ & $\dot{x}_{3}=\frac{V_{i n_{3}}}{L_{3}}$ \\
$\dot{x}_{4}=0$ & $\dot{x}_{4}=\frac{x_{2}}{C_{1}}$ & $\dot{x}_{4}=0$ & $\dot{x}_{4}=-\frac{x_{1}}{C_{1}}$ \\
$\dot{x}_{5}=0$ & $\dot{x}_{5}=-\frac{x_{2}}{C_{2}}$ & $\dot{x}_{5}=\frac{x_{3}}{C_{2}}$ & $\dot{x}_{5}=0$ \\
$\dot{x}_{6}=-\frac{x_{6}}{R_{L} C_{o}}$ & $\dot{x}_{6}=-\frac{x_{6}}{R_{L} C_{o}}$ & $\dot{x}_{6}=-\frac{x_{6}}{R_{L} C_{o}}$ & $\dot{x}_{6}=-\frac{x_{1}}{C_{o}}-\frac{x_{6}}{R_{L} C_{o}}$ \\
\hline
\end{tabular}

Let us introduce the notation for every switch state:

$$
u_{n}=\left\{\begin{array}{ccc}
1 & \text { if } & s w_{n}=\text { off } \\
0 & \text { if } & s w_{n}=o n
\end{array}\right\}, n=1,2,3
$$

Then, the following general state space representation can be obtained:

$$
\left[\begin{array}{l}
\dot{x}_{1} \\
\dot{x}_{2} \\
\dot{x}_{3} \\
\dot{x}_{4} \\
\dot{x}_{5} \\
\dot{x}_{6}
\end{array}\right]=\left[\begin{array}{cccccc}
0 & 0 & 0 & \frac{u_{1}}{L_{1}} & 0 & -\frac{u_{1}}{L_{1}} \\
0 & 0 & 0 & -\frac{u_{2}}{L_{2}} & \frac{u_{2}}{L_{2}} & 0 \\
0 & 0 & 0 & 0 & -\frac{u_{3}}{L_{3}} & 0 \\
-\frac{u_{1}}{C_{1}} & \frac{u_{2}}{C_{1}} & 0 & 0 & 0 & 0 \\
0 & -\frac{u_{2}}{C_{2}} & \frac{u_{3}}{C_{2}} & 0 & 0 & 0 \\
\frac{u_{1}}{C_{0}} & 0 & 0 & 0 & 0 & -\frac{1}{R_{L} C_{0}}
\end{array}\right]\left[\begin{array}{c}
x_{1} \\
x_{2} \\
x_{3} \\
x_{4} \\
x_{5} \\
x_{6}
\end{array}\right]+\left[\begin{array}{c}
\frac{V_{i n 1}}{L_{1}} \\
\frac{V_{\text {in } 2}}{L_{2}} \\
\frac{V_{i n 3}}{L} \\
3 \\
0 \\
0 \\
0 \\
0
\end{array}\right]
$$

\section{Design Procedure and Simulation Results}

Although the converter uses three different input voltages, components are designed considering the lowest voltage, $V_{\text {in min }}$; due to inductors, current is maximum under this condition.

The complete development of the converter design equations was derived in [12] for the two-input case. Generalization of these equations was obtained from the operating modes described in the previous section. The gain for a three-input converter, $M_{V D C}$, is:

$$
M_{V D C}=\frac{V_{o}}{V_{i n}}=\frac{3}{1-d}=\frac{3 I_{i n n}}{I_{o}},
$$

where $d$ is the duty cycle of switching devices operation, and $I_{i n n}$ is the input current for each source. The duty cycle is determined according to an open loop control, where the 
output power or the voltage gain, $M_{V D C}$, are specified. To calculate inductance values, note that the inputs of the converter are the same as the conventional boost converter, hence:

$$
L_{n}=\frac{V_{i n} d}{\Delta I_{n} f_{s}},
$$

where $\Delta I_{n}$ is the ripple current of inductor, and $f_{s}$ is the switching frequency.

Capacitors $C_{1}$ and $C_{2}$ were carefully designed, since a small value may generate an inadequate conversion ratio, and a very large value will affect the time response and create output voltage oscillations. Note that voltage on capacitors $C_{1}$ and $C_{2}$ affect the output voltage only through inductor currents. This can be observed from state equations, particularly from the output voltage equation; the output voltage derivative only depends on the output voltage, itself, the current $x 1$, the load and the output capacitor. Hence, ripple voltage in these capacitors can have a wide range, since this ripple is not reflected at the converter output. As it is proved in [12], the capacitors can be calculated according to:

$$
\begin{aligned}
& C_{1}=\frac{I_{o}\left(1-d_{1}\right)}{d_{2} \Delta V_{c 1} f_{s}}, \\
& C_{2}=\frac{I_{o}\left(1-d_{2}\right)}{d_{3} \Delta V_{c 2} f_{s}} \\
& C_{o}=\frac{I_{o}\left(1-d_{1}\right)}{\Delta V_{o} f_{s}}
\end{aligned}
$$

where $I_{o}$ is the output current and $\Delta V_{C 1}, \Delta V_{C 2}, \Delta V_{C o}$ are the ripple voltage of $C_{1}, C_{2}$ and $C_{o}$ respectively.

The converter output voltage is given by:

$$
V_{o}=\frac{V_{i n 1}}{1-d_{1}}+\frac{V_{i n 2}}{1-d_{2}}+\frac{V_{i n 3}}{1-d_{3}},
$$

Using Equations (10)-(13), the final component values are obtained and listed in Table 2, together with the design conditions. A simulation was performed in Saber ${ }^{\mathrm{TM}}$ using ideal components to validate the design procedure and the correct operation of the three-input step-up converter.

Table 2. Test parameters and components.

\begin{tabular}{cc}
\hline Parameter & Value \\
\hline Lowest input voltage, $V_{\text {in } \min }$ & $12 \mathrm{~V}$ \\
First input voltage source, $V_{i n 1}$ & $12 \mathrm{~V}$ \\
Second input voltage source, $V_{\text {in } 2}$ & $24 \mathrm{~V}$ \\
Third voltage source, $V_{\text {in } 3}$ & $48 \mathrm{~V}$ \\
Output voltage, $V_{o}$ & $190 \mathrm{~V}$ \\
Output current, $I_{o}$ & $5.2 \mathrm{~A}$ \\
Output power, $P_{o}$ & $1000 \mathrm{~W}$ \\
Switching frequency, $f_{s}$ & $100 \mathrm{kHz}$ \\
Voltage gain, $M_{V D C}$ & 15.7 \\
Duty cycle, $d_{n}$ & $0.66 \sim 0.8$ \\
Phase shift & $120^{\circ}$ \\
Voltage ripple in $C_{1}, \Delta V_{c p 1}$ & $50 \mathrm{~V}$ \\
Voltage ripple in $C_{2}, \Delta V_{c p 2}$ & $100 \mathrm{~V}$ \\
Output voltage ripple, $\Delta V_{o}$ & $2 \mathrm{~V}$ \\
Inductors, $L_{1}, L_{2}, L_{3}$ & $47 \mu \mathrm{H}$ \\
Capacitor $C_{1}$ & $0.1 \mu \mathrm{F}$ \\
Capacitor $C_{2}$ & $0.2 \mu \mathrm{F}$ \\
Capacitor $C_{o}$ & $20 \mu \mathrm{F}$ \\
Output load, $R_{o}$ & $33 \Omega$ \\
\hline
\end{tabular}


Control signals S1, S2 and S3 are shown in Figure 4 with a phase shift $\varphi=120^{\circ}$ and $d=0.72$ The voltages $V_{L 1}, V_{L 2}$ and $V_{L 3}$ and currents $I_{L 1}, I_{L 2}$ and $I_{L 3}$ are shown in Figures $5-7$, respectively. They can be contrasted with the ideal waveforms of Figure 3 to verify the correct operation of the converter.

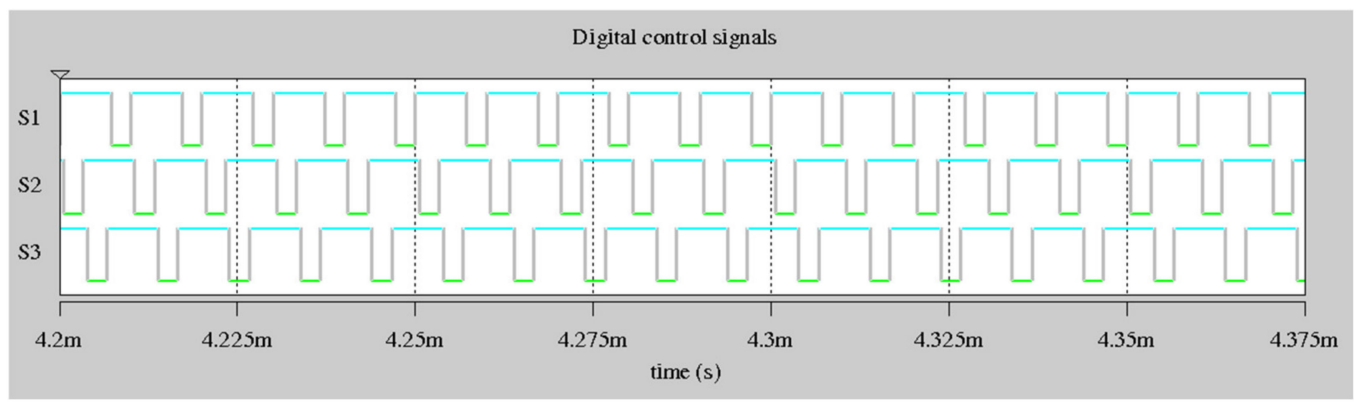

Figure 4. Simulation results for digital control signal $S 1, S 2, S 3$ with $\varphi=120^{\circ}$ and $d=0.72$.

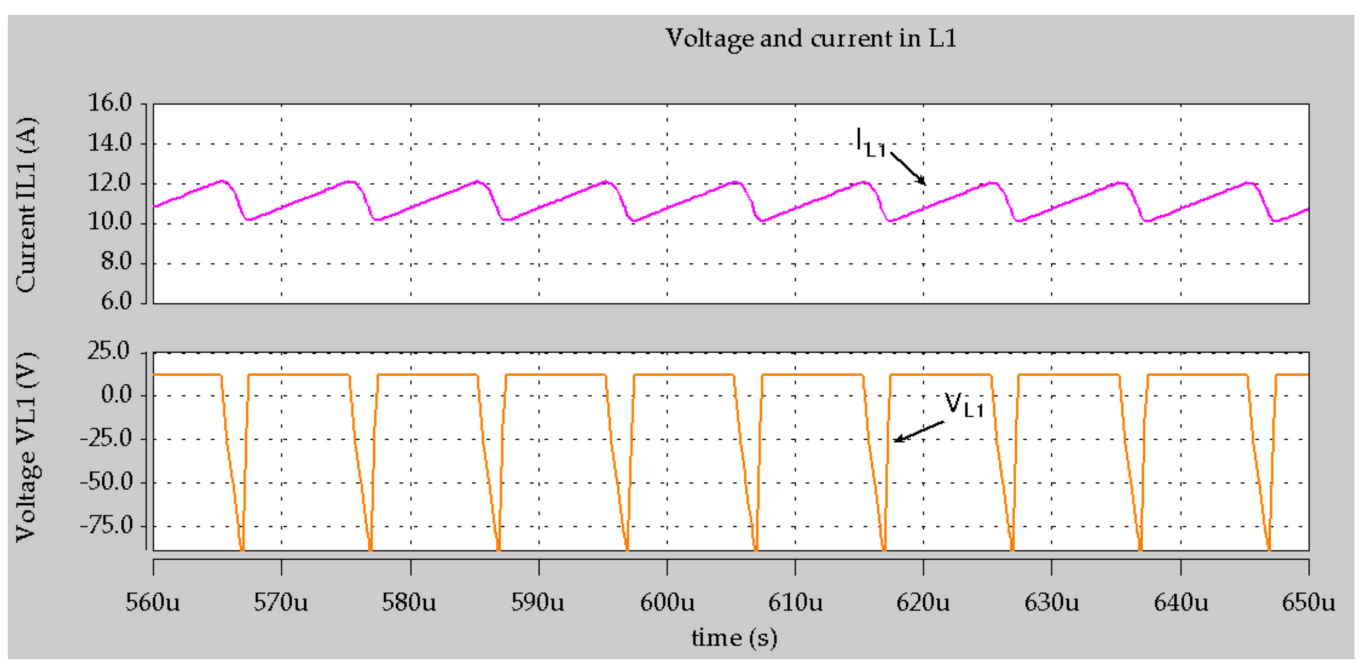

Figure 5. Simulation results for $I_{L 1}$ and $V_{L 1}$.

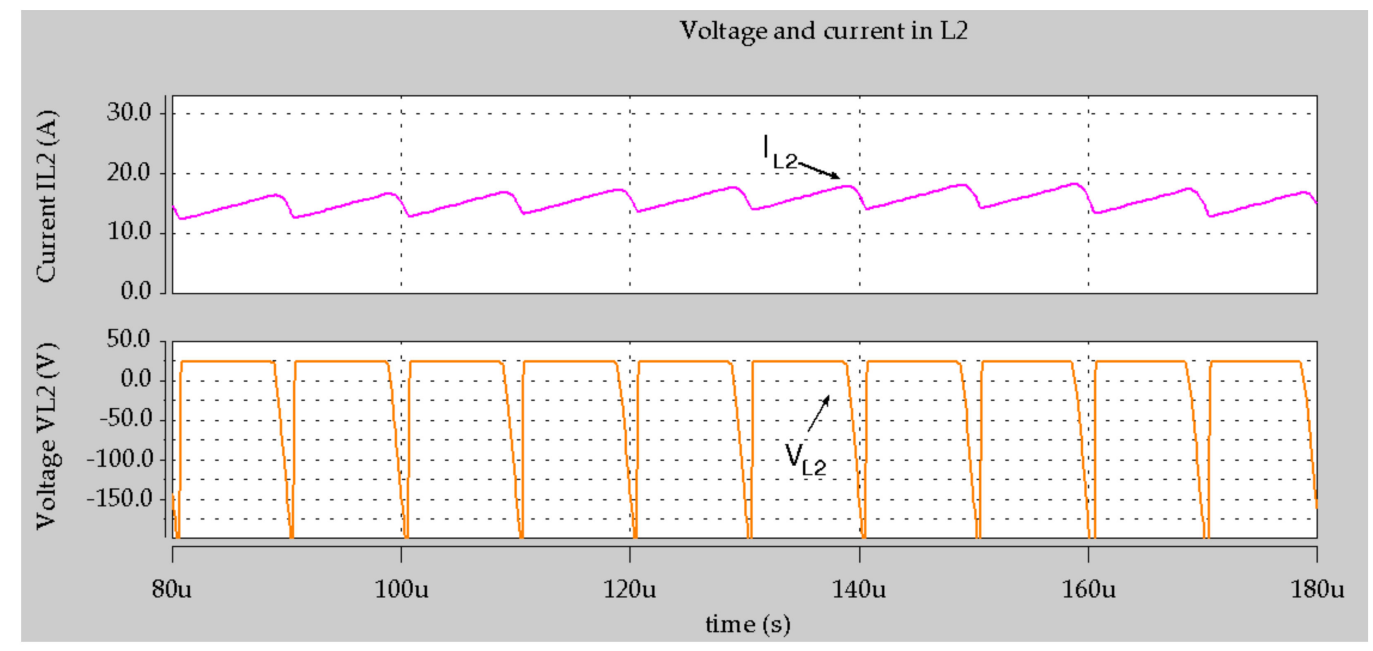

Figure 6. Simulation results for $I_{L 2}$ and $V_{L 2}$. 


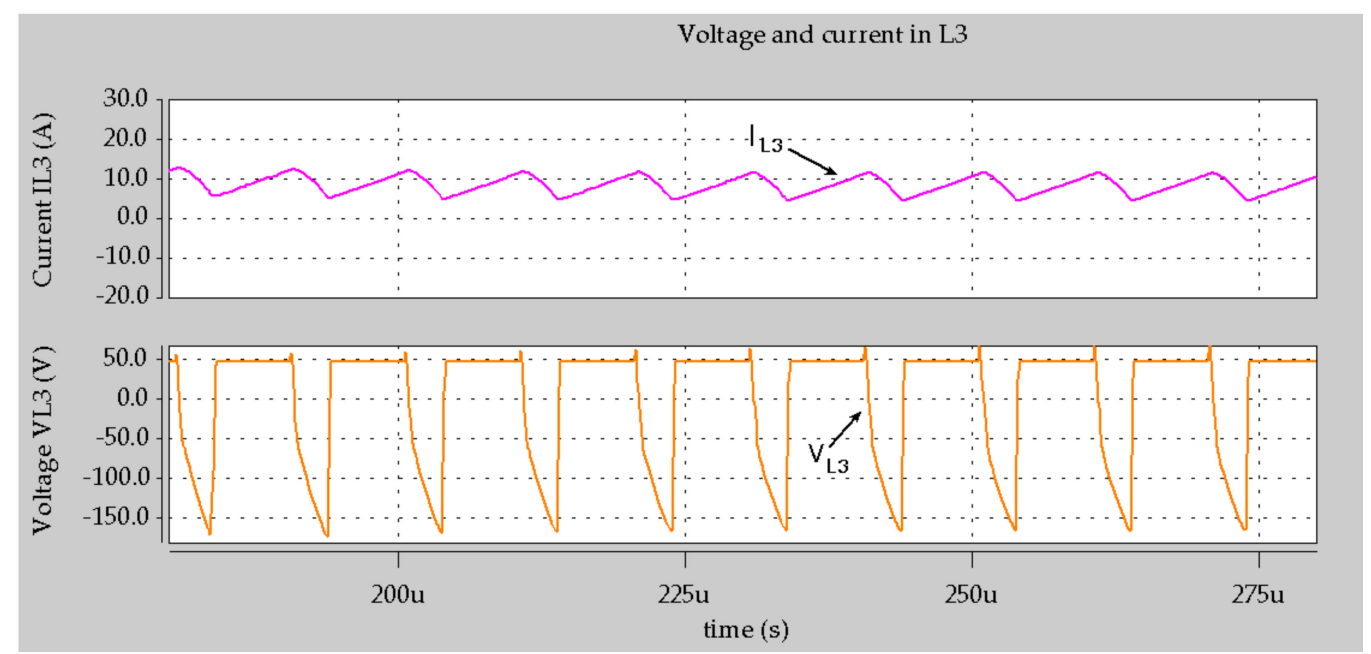

Figure 7. Simulation results for $I_{L 3}$ and $V_{L 3}$.

Simulation results for output voltage and current, $V_{o}$ and $I_{o}$ are shown in Figure 8 with DC (average) values $V_{O D C}=193.39 \mathrm{~V}$ and $I_{O D C}=5.52 \mathrm{~A}$, getting an output power of $P_{o}=1.067 \mathrm{~kW}$. The ripple voltage obtained $\Delta V_{o}=951 \mathrm{mV}$.

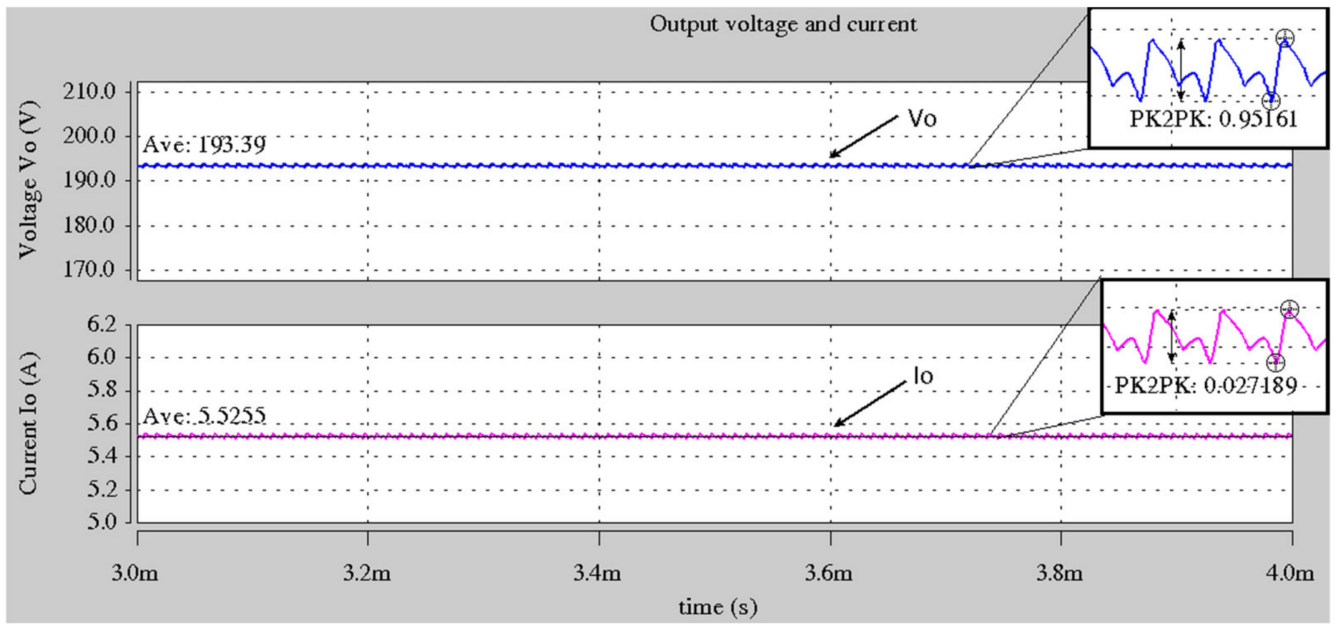

Figure 8. Simulation results for $V_{o}$ and $I_{o}$.

\section{Experimental Results}

Considering that the maximum drain-source voltage is the output voltage, $\mathrm{SiC}$ transistors CMF20120 and diodes C3 D06060 were employed to reduce switching losses in the implemented prototype. The NXP TWR-KV 58 F220 microcontroller was used to generate the PWM pulses with a phase shifted of $120^{\circ}$. Inductors were designed and constructed, following the methodology presented in [14].

The efficiency of the converter is determined by:

$$
\eta=\frac{P_{o}}{P_{i n_{1}}+P_{i n_{2}}+P_{i n_{3}}},
$$

The measure input current values were:

$$
\begin{gathered}
I_{i n_{1}}=12.5 \mathrm{~A}, I_{i n_{2}}=18.5 \mathrm{~A}, I_{i n_{3}}=11.5 \mathrm{~A} \\
V_{i n_{1}}=12 \mathrm{~V}, V_{i n_{2}}=24 \mathrm{~V}, V_{i n_{3}}=48 \mathrm{~V}
\end{gathered}
$$


The implemented prototype can be seen in Figure 9, where the main components are indicated. Output voltage and current are shown in Figure 10; obtained multimeter measurements are 190.9 $\mathrm{V}_{\mathrm{DC}}$ and $5.4 \mathrm{~A}_{\mathrm{DC}}$. In Figure 11, it can be seen that the output voltage is $192.09 \mathrm{~V}_{\mathrm{DC}}$, with ripple voltage of $1.005 \mathrm{~V}_{\mathrm{RMS}}$, resulting in an output power of $P_{0}=1.037 \mathrm{~kW}$.

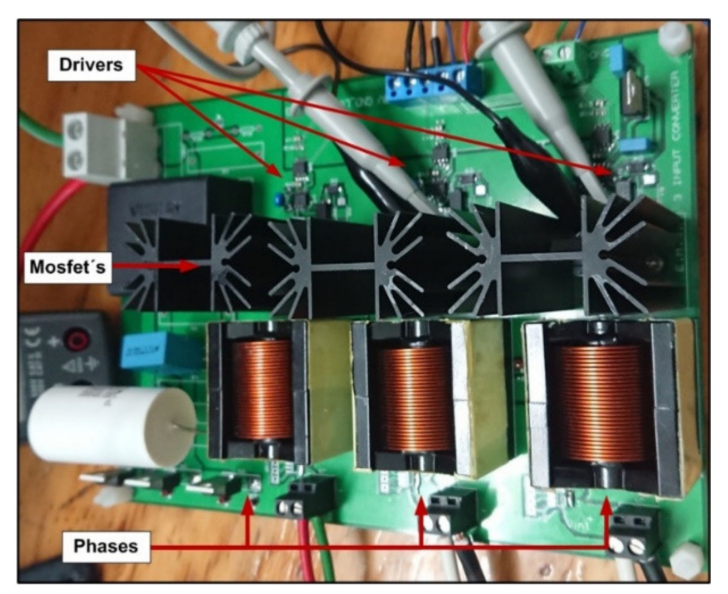

Figure 9. Implemented $1 \mathrm{~kW}$ prototype.

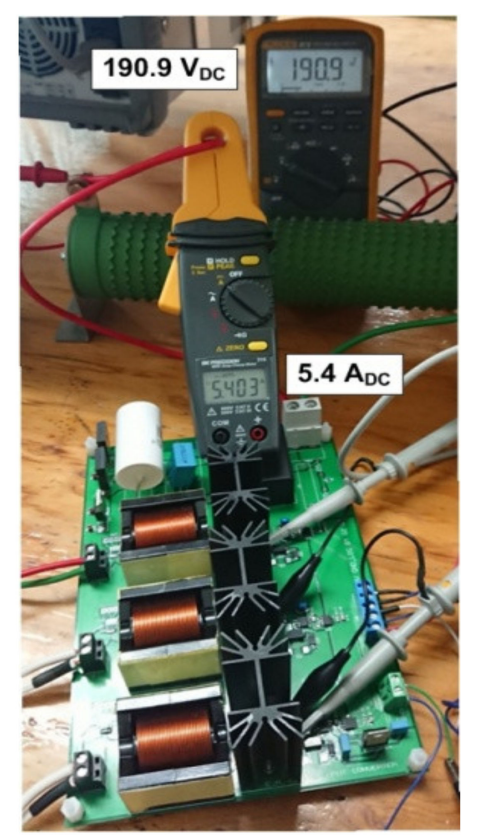

Figure 10. Implemented $1 \mathrm{~kW}$ prototype with voltage and current measurement.

In Figure 12, voltage and current waveforms of inductors $L_{1}, L_{2}$ and $L_{3}$ are shown. Positive amplitudes in voltage waveforms are approximately equal to the value of the corresponding input voltage supply. A comparison of these waveforms with the ideal waveforms of Figures 3 and 5-8 shows their similarity, validating the experimental results. Spikes and high-amplitude ripples observed in the experimental waveforms show the existence of parasitic components that are not considered in simulation. 


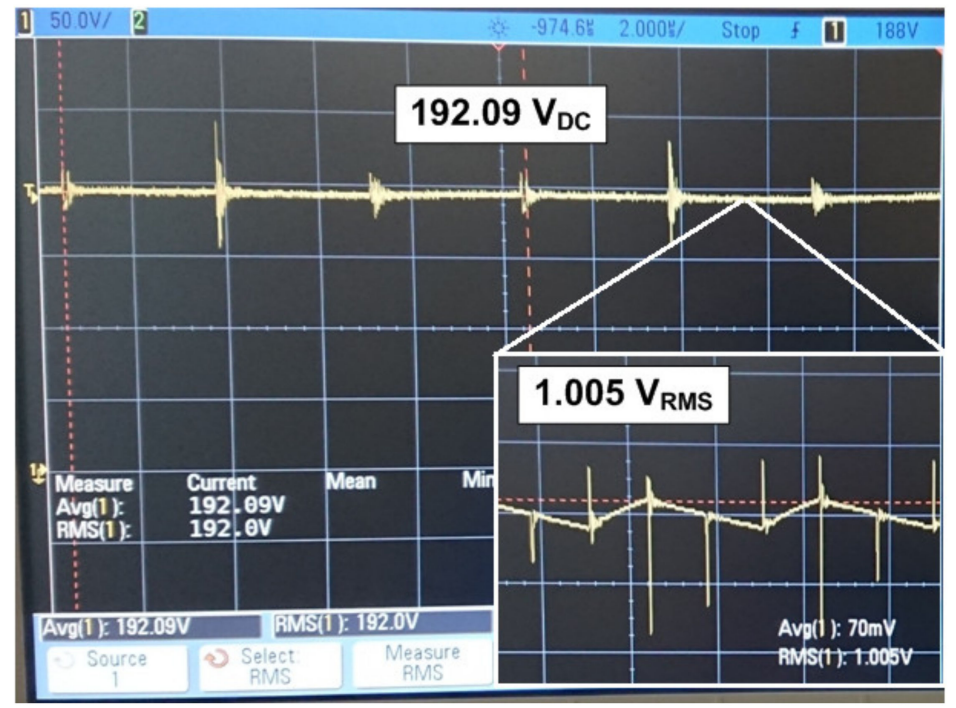

Figure 11. Experimental results $V_{o}=192.09 \mathrm{~V}_{\mathrm{DC}}, \Delta V_{o}=1.005 \mathrm{~V}$.

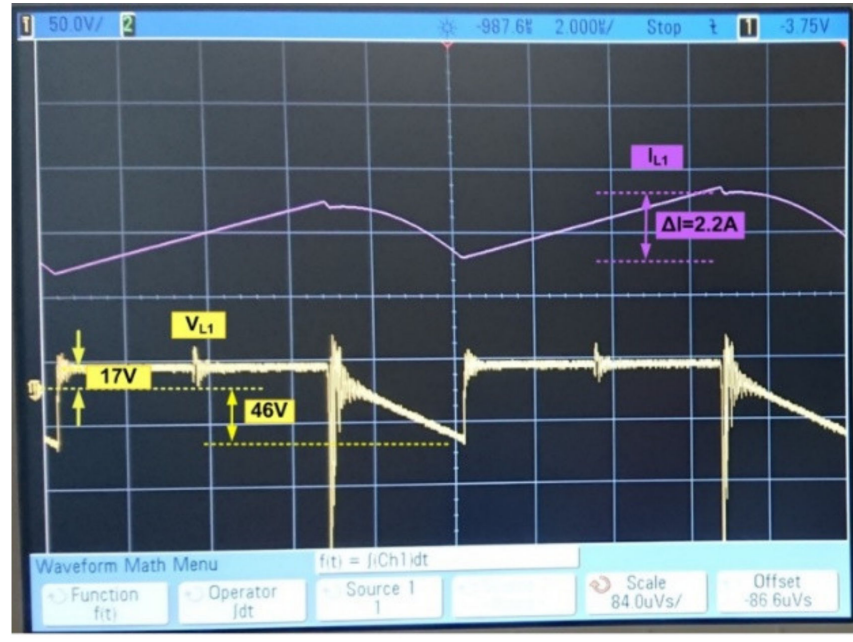

(a)

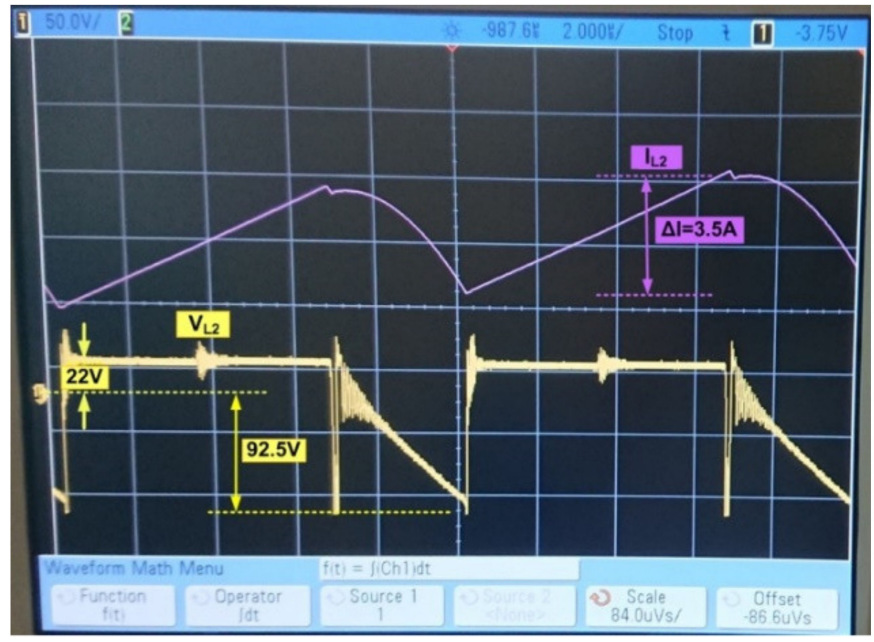

(b)

Figure 12. Cont. 


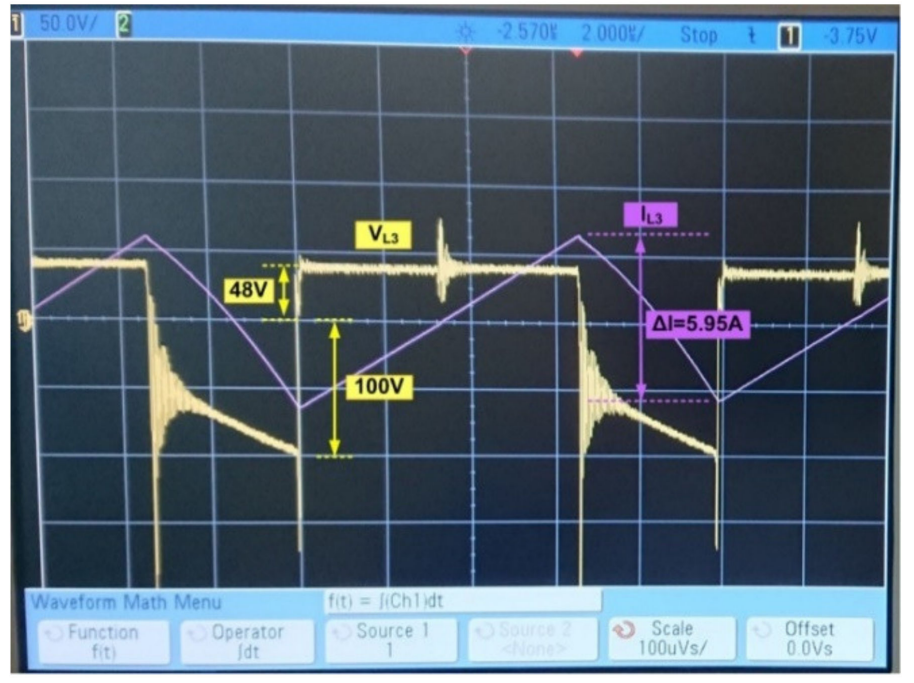

(c)

Figure 12. Experimental results: (a) $V_{L 1}$ and $I_{L 1}$, input voltage $V_{\text {in } 1}=12 \mathrm{~V}$, (b) $V_{L 2}$ and $I_{L 2}$, input voltage $V_{\text {in } 2}=24 \mathrm{~V}$, (c) $V_{L 3}$ and $I_{L 3}$, input voltage $V_{\text {in } 2}=48 \mathrm{~V}$.

According to Equation (15), and using the input voltages and currents, the efficiency obtained is $\eta=90.51 \%$. Figure 13 shows the experimental set up: (a) three-input step-up converter, (b) three input voltage sources, (c) the PWM signal generator and (d) the $33 \Omega$ output load.

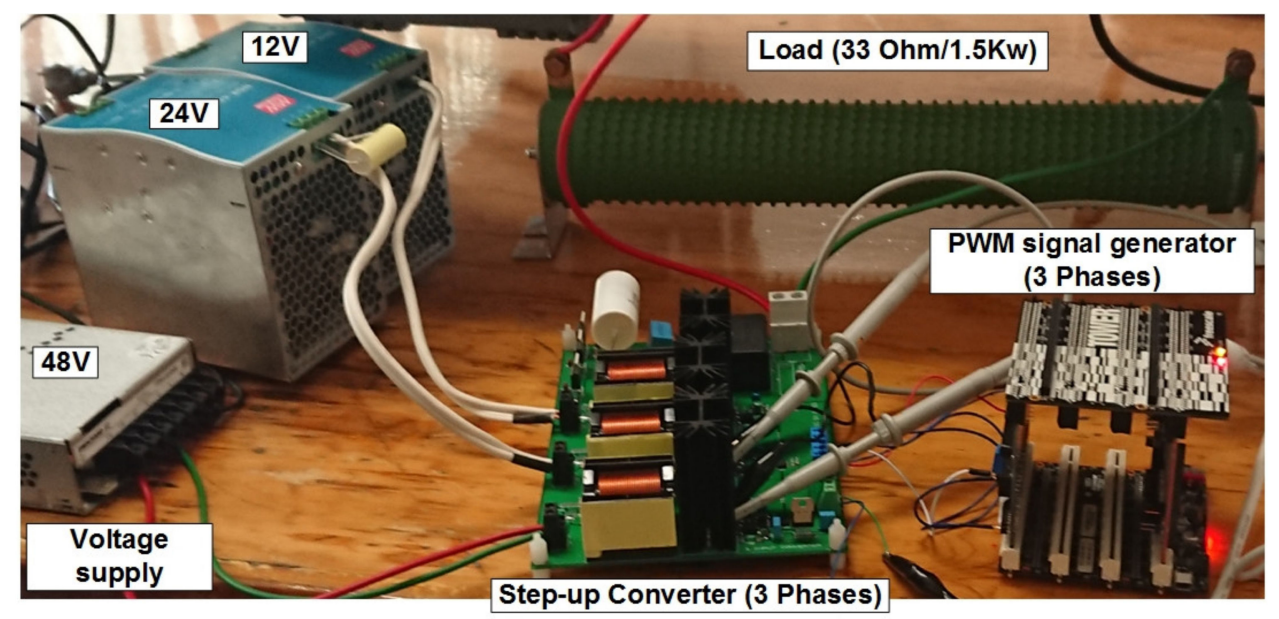

Figure 13. Experimental prototype with three input voltage sources, $33 \Omega$ output load and the PWM signal generator.

A comparison between the proposed converter and similar topologies is summarized in Table 3. The implemented converter provides the highest output power, keeping a high efficiency, considering three voltage sources in its design. The number of energy storage elements is less than the converters proposed in $[9-12,15,16]$. The high switching frequency $(100 \mathrm{kHz})$ is a factor to reduce its implementation size. 
Table 3. A comparison between the proposed converter and similar topologies.

\begin{tabular}{|c|c|c|c|c|c|c|c|}
\hline Factor/Topologies & $\begin{array}{l}\text { Proposed } \\
\text { High-Gain } \\
\text { Three-Input } \\
\text { Step-Up } \\
\text { Converter }\end{array}$ & $\begin{array}{c}\text { High Step-Up } \\
\text { Multi-Input } \\
\text { Multi-Output } \\
\text { Converter [9] }\end{array}$ & $\begin{array}{l}\text { Soft-Switched } \\
\text { Step-Up } \\
\text { Converter [10] }\end{array}$ & $\begin{array}{c}\text { Modular } \\
\text { Step-Up } \\
\text { Converter [11] }\end{array}$ & $\begin{array}{c}\text { High-Gain } \\
\text { Two-Input } \\
\text { Step-Up } \\
\text { Converter [12] }\end{array}$ & $\begin{array}{c}\text { Multiphase } \\
\text { Buck } \\
\text { Converter [15] }\end{array}$ & $\begin{array}{c}\text { Multi-Input } \\
\text { Multi-Output } \\
\text { [16] }\end{array}$ \\
\hline $\begin{array}{l}\text { Open-loop } \\
\text { current } \\
\text { unbalance }\end{array}$ & Minimum & Minimum & Minimum & Medium & Minimum & Medium & Medium \\
\hline Output power & $1.037 \mathrm{~kW}$ & $\begin{array}{l}1 \mathrm{~kW} \text { (divided } \\
\text { in } 2 \text { outputs) }\end{array}$ & $125 \mathrm{~W}$ & $200 \mathrm{~W}$ & $500 \mathrm{~W}$ & $152 \mathrm{~W}$ & $100 \mathrm{~W}$ \\
\hline Efficiency & $90.51 \%$ & $75-96.8 \%$ & $97 \%$ & $87 \%$ & $90-95 \%$ & $87-95 \%$ & $86 \%$ \\
\hline $\begin{array}{c}\text { Number of } \\
\text { voltage sources }\end{array}$ & 3 & 4 & 2 & 2 & 2 & 2 & 2 \\
\hline Input voltage & $24 \mathrm{~V}, 12 \mathrm{~V}, 48 \mathrm{~V}$ & $52 \mathrm{~V}, 40 \mathrm{~V}, 50 \mathrm{~V}$ & $24 \mathrm{~V}, 20 \mathrm{~V}$ & $10 \mathrm{~V}, 10 \mathrm{~V}$ & $24 \mathrm{~V}, 24 \mathrm{~V}$ & $100 \mathrm{~V}, 50 \mathrm{~V}$ & $60 \mathrm{~V}, 12 \mathrm{~V}$ \\
\hline Output voltage & $190 \mathrm{~V}$ & $453 \mathrm{~V}, 322 \mathrm{~V}$ & $200 \mathrm{~V}$ & $250 \mathrm{~V}$ & $186.6 \mathrm{~V}$ & $18.5 \mathrm{~V}$ & $48 \mathrm{~V}$ \\
\hline $\begin{array}{l}\text { Number of } \\
\text { power } \\
\text { switching } \\
\text { devices }\end{array}$ & 3 & 4 & 4 & 7 & 2 & 5 & 4 \\
\hline $\begin{array}{l}\text { Number of } \\
\text { diodes }\end{array}$ & 3 & 7 & 4 & 1 & 2 & 2 & 6 \\
\hline $\begin{array}{l}\text { Number of } \\
\text { inductors }\end{array}$ & 3 & 7 & 3 & 4 & 2 & 1 & 3 \\
\hline $\begin{array}{l}\text { Number of } \\
\text { capacitors }\end{array}$ & 3 & 4 & 3 & 4 & 2 & 1 & 5 \\
\hline $\begin{array}{l}\text { Switching } \\
\text { frequency }\end{array}$ & $100 \mathrm{kHz}$ & $40 \mathrm{kHz}$ & $100 \mathrm{kHz}$ & $25 \mathrm{kHz}$ & $100 \mathrm{kHz}$ & $10 \mathrm{kHz}$ & $100 \mathrm{kHz}$ \\
\hline
\end{tabular}

\section{Conclusions}

A high-gain three-input step-up converter of $1 \mathrm{~kW}$ was analyzed, designed and implemented. The design procedure was validated through experimental results. In addition, the converter efficiency and reliability were verified, obtaining a power of $1037 \mathrm{~W}$, with an efficiency of $90.51 \%$, which is superior to similar proposals. The converter topology can be used for a wide range of applications; in particular, the topology could be used as a low-cost alternative to jointly use several renewable sources that may be backed up by a nonrenewable source, allowing the prioritization of power sources at any time. Based on the obtained results, it can be said that the converter topology can be used for higher powers and more inputs.

Author Contributions: Conceptualization, E.N.-H., L.H.-G. and D.C.; data curation, J.R.-H. and D.C.; formal analysis, L.H.-G., D.C. and J.R.-H.; funding acquisition, E.N.-H. and L.H.-G.; investigation, E.N.-H., L.H.-G., D.C. and J.R.-H.; methodology, E.N.-H. and L.H.-G.; project administration, L.H.-G.; resources, D.C. and J.R.-H.; software, E.N.-H., L.H.-G. and J.R.-H.; supervision, L.H.-G. and D.C.; validation, E.N.-H. and L.H.-G.; visualization, E.N.-H. and L.H.-G.; writing, original draft, E.N.-H. and L.H.-G.; writing, review and editing, D.C. and J.R.-H. All authors have read and agreed to the published version of the manuscript.

Funding: This research was funded by Instituto Politécnico Nacional.

Acknowledgments: The authors are grateful to the Instituto Politécnico Nacional (IPN) for their encouragement and kind economic support to realize the research project.

Conflicts of Interest: The authors declare no conflict of interest. 


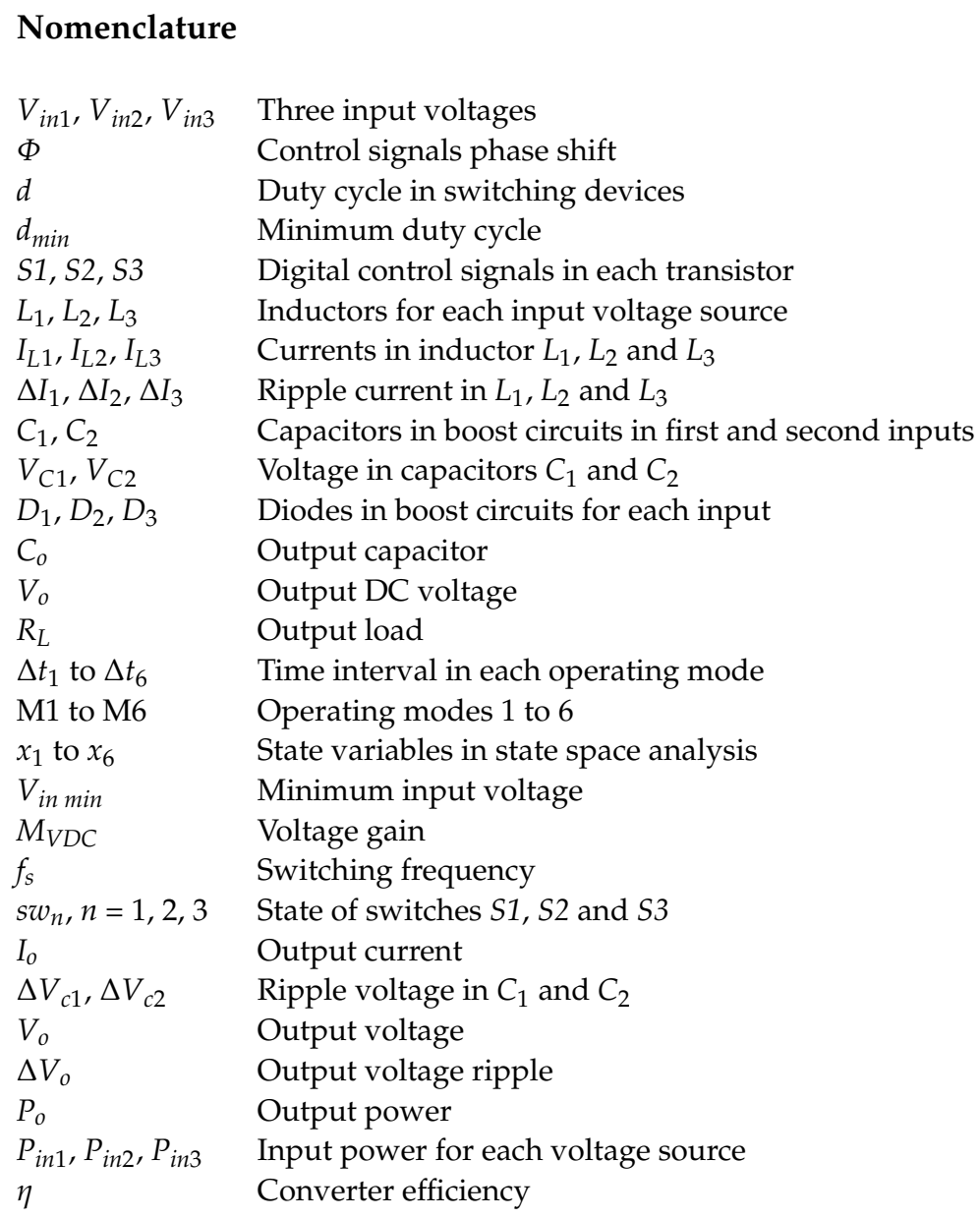

\section{References}

1. Prasanth, J.; Rajasekar, N. A Novel Flower Pollination Based Global Maximum Power Point Method for Solar Maximum Power Point Tracking. IEEE Trans. Power Electron. 2015, 32, 8486-8499. [CrossRef]

2. Yaramasu, V.; Dekka, A.; Durán, M.; Kouro, S.; Wu, B. PMSG-based wind energy conversion systems: Survey on power converters and controls. IET Electr. Power Appl. 2017, 11, 956-968. [CrossRef]

3. Teng, Y.; Wang, Z.; Li, Y.; Ma, Q.; Hui, Q.; Li, S. Multi-energy storage system model based on electricity heat and hydrogen coordinated optimization for power grid flexibility. CSEE J. Power Energy Syst. 2019, 5, 266-274.

4. Liu, Y.-C.; Chen, Y.-M. A Systematic Approach to Synthesizing Multi-Input DC-DC Converters. IEEE Trans. Power Electron. 2009, 24, 116-127. [CrossRef]

5. Chew, Z.J.; Ruan, T.; Zhu, M. Power Management Circuit for Wireless Sensor Nodes Powered by Energy Harvesting: On the Synergy of Harvester and Load. IEEE Trans. Power Electron. 2018, 34, 8671-8681. [CrossRef]

6. Pooranian, Z.; Abawajy, J.H.; Vinod, P.; Mauro, C. Scheduling Distributed Energy Resource Operation and Daily Power Consumption for a Smart Building to Optimize Economic and Environmental Parameters. Energies 2018, 11, 348. [CrossRef]

7. Zhang, Y.; He, J.; Ionel, D.M. Modelling and Control of a Multiport Converter based EV Charging Station with PV and Battery. In Proceedings of the IEEE Transportation Electrification Conference, Detroit, MI, USA, 1-5 June 2019.

8. Schumacher, D.; Beik, O.; Emadi, A. Standalone Integrated Power Electronics System: Applications for Off-Grid Rural Locations. IEEE Electrif. Mag. 2018, 6, 73-82. [CrossRef]

9. Mohseni, P.; Hossein, H.S.; Sabahi, M.; Jalilzadeh, T.; Maalandish, M. A New High Step-Up Multi-Input Multi-Output DC-DC Converter. IEEE Trans. Ind. Electron. 2019, 66, 5197-5208. [CrossRef]

10. Faraji, R.; Farzanehfard, H.; Kampitsis, G.; Mattavelli, M.; Matioli, E.; Esteki, M. Fully Soft-Switched High Step-Up Nonisolated Three-Port DC-DC Converter Using GaN HEMTs. IEEE Trans. Ind. Electron. 2010, 67, 8371-8380. [CrossRef]

11. Varesi, K.; Hossein, H.S.; Sabahi, M.; Babaei, E. Modular non-isolated multi-input high step-up dc-dc converter with reduced normalised voltage stress and component count. IET Power Electron. 2018, 11, 1092-1100. [CrossRef]

12. Netzahuatl, E.; Cortes, D.; Ramirez-Salinas, M.A.; Resa, J.; Hernandez, L.; Hernandez, F.D. Modeling, Design Procedure and Control of a Low-Cost High-Gain Multi-Input Step-Up Converter. Electronics 2019, 8, 424. [CrossRef]

13. Zhou, L.; Zhu, B.; Luo, Q. High step-up converter with capacity of multiple input. IET Power Electron. 2012, 5, 524-531. [CrossRef]

14. McLyman, C.W.T. Transformer and Inductor Design Handbook; CRC Press: Boca Raton, FL, USA, 2017; ISBN 9781439836880. 
15. Varesi, K.; Hossein, H.S.; Sabahi, M.; Babei, E.; Vosoughi, N. Performance and design analysis of an improved non-isolated multiple input buck DC-DC converter. IET Power Electron. 2017, 10, 1034-1045. [CrossRef]

16. Sun, Z.; Bae, S. Multiple-input Soft-switching Ćuk Converter. In Proceedings of the IEEE Energy Conversion Congress and Exposition, Cincinnati, OH, USA, 1-5 October 2017. 